\title{
The Effect of Organizational Justice on Job Satisfaction Among Secondary School Teachers
}

\author{
LAITH Ali Zgair Ghran ${ }^{1}$, ALAA S. Jameel ${ }^{2}$, ABD Rahman Ahmad ${ }^{3}$ \\ ${ }^{1}$ Al-Furat Al-Awsat Technical University (IRAQ) \\ ${ }^{2}$ Department of Public Administration, Cihan University-Erbil, Kurdistan Region, Iraq, Faculty of Technology Management \\ and Business, Universiti Tun Hussein Onn (MALAYSIA) \\ ${ }^{3}$ Faculty of Technology Management and Business, Universiti Tun Hussein Onn (MALAYSIA) \\ Emails: Laith571982@yahoo.com, alaa.salam@cihanuniversity.edu.iq,arahman@uthm.edu.my
}

\begin{abstract}
Job satisfaction and organizational justice one of the topics which neglected in the context of Middle East countries in general and particularly in Iraq. The study aims to find the effect of organizational justice on job satisfaction among secondary schools' teachers and enrich the body of knowledge in Iraq and the Middle East countries. The study conducted in 8 secondary schools in Heet city province of Anbar, Iraq, 98 valid questionnaires were analysed by SPSS.

The results showed the components of organizational justice's distributive justice and interactional justice are positively affect on job satisfaction. However, distributive justice found a high effect on Job satisfaction. While, Procedural justice found non-significant effect on job satisfaction may because of the environment and policy of public schools in Iraq which is directly related to government policy in case of, promotions, salary and employment etc.

This result helps school's administration to manage the schools and understand teachers desire better than before. Meanwhile, teachers, when feel treated fairly from school administration and the rewards are distributed fairly and equitable in the school will lead to increase job satisfaction and could increase their productivity and performance.
\end{abstract}

Keywords: organizational justice, job satisfaction, secondary school, Teachers and Iraq

JEL: I20

UDK: 005.42-024.61

005.32:331.101.32]:371.12

\section{Introduction}

Job satisfaction (JS) one of the focal points of several studies and attracts the attention of scholars and researchers until now. Job satisfaction considers an important factor in every work environment which can lead the success in any workplace. According to [1] job satisfaction refers to the attitude that clarifies the level of individual feeling related to their job. However, organizational justice (OJ) refers to employee's assessment to fairness, equal and equality treatment in the workplace. Exercising justice in the workplace from management lead to achieving organizational objectives and gain a succeed [2]. Create and provide a justice climate in organizations will positively reflect on employee's motivation and performance [3], when treat employees fairly in an organization they will do their duty in a good way, however, when they feel, treat unfairly will lead to low job satisfaction in workplace [4]. Nevertheless, organizational justice consists of several dimensions that comprise various facets procedural justice (PJ), distributive justice (DJ) and interactional justice (IJ) [5], and job satisfaction 
consists of several dimensions pay, promotion, co-work, supervision, job condition [1]. A number of studies has been conducted to exam the association and impact of (OJ) on (JS) [2], [3], [24], [30].

However, limited studies conducted in Middle East countries as well, developing countries [30], [4] and particularly in Iraq. Furthermore, most of the previous studies conducted in western countries or south-east Asia countries and the culture, environment and processes in Iraq and Middle East countries are totally different about these countries. Thus, it is eligible to examine this topic in Iraq context. the purpose of this study to find and exam the impact of (OJ) dimensions on (JS) in Iraq setting and particularly in the education field, among secondary schools' teachers in Heet city - the province of Al Anbar, Iraq.

\section{Literature Review}

\section{Job Satisfaction}

Brief [6], [1] defined JS as individuals' feelings and attitudes toward their job in different aspects. The feelings towards JS is the difference between the rewards and appreciation received by individuals and what expected to receive. JS is positive or negative feelings and attitudes of individuals towards their job [7]. However, individuals with a high level of satisfaction could lead to a positive attitude and low level of satisfaction may lead to a negative attitude in workplace [8]. High level of job satisfaction considers important for individuals to increase their performance and to the organizations to gain the success [9], [10].

Regardless of positive attitude [7] mentioned the negative experiences for employees consider one of the elements leads to dissatisfaction with current working. As well, one of the significant elements may occur for job dissatisfaction by experiences among the employees' is (OJ). According to [1] there are serval dimensions of (JS) namely: pay, supervision, promotion, co-workers and work itself, appreciation, communication, fringe benefits, job conditions recognition and security. All the above dimensions are fitting to measure job satisfaction, this study will select some of these dimensions, because difficult to cover all the dimensions in one study.

\section{Organizational Justice}

Since 1987 by Greenberg OJ has been developed to multidimensional variables, and define organizational justice as to how fairly individuals treated by the organization and how their perception toward the organization justice [5]. The fair treatment of employees in workplace leads to creating a high level of trust in an organization [11]. The three dimensions of justice have been widely accepted among the researchers and scholars namely; Distributive justice, Procedural justice, and Interactional justice. However, [12] reported staff members in organizations assess fair treatment on three dimensions distributive justice (DJ), procedural justice (PJ) and interpersonal justice (IJ).

\section{Distributive Justice}

(DJ) refers to organizational outcomes should be fair and equitable through payment, job assessment, benefits, discipline, and promotion [13], [16] mentioned distributive justice refers to equity and not equality. Equality indicate to all the individuals in the workplace considered their efforts as the same and no matter which one more impact or which one high performance between each other in the workplace. However, equality defined by [15] all the individual treated as a same regardless of their performance or impact they have. Equity refer to the contribution and efforts made by a particular individual in the workplace [31], [18]. Related to the principle of equity exchange employees usually compare what other colleagues in same 
level and situations received and then evaluate whether is it fair or unfair [17]. On other words Individual assess what they and others achieved and what they and others received.

Employees evaluate the fairness of organization outcome by compeering between the input which reflects in time, efforts and outcomes that received such as pay and promotions [12].

\section{Procedural Justice}

[20] confirmed that (PJ) as the second dimension of justice rules. However, procedural justice refers to the operations and procedures that the institution depends on to achieve the results is fair [13], [31]. Individuals looking to the, open and fair, procedures regardless of the outcome [15]. The fair and just of the processes and procedures could be more essential than the results itself [18]. [19] and defined (PJ) as the assessment of the decision-making process in an organization and the degree of equitable of this decision. However, [20] described the procedural justice it is how the decisions are clearly, ethical, reliable and correctable.

\section{Interactional Justice}

Created by [21] this dimension as the third one which describes and explains organizational justice, and refers to the fair received by individuals through resource allocation and decision making. However, Interactional justice refers to honesty, respect, and integrity with subordinates [21], [2] defined interactional justice as a free flow of information among individuals within the organisation, and managers should concern of employees needs and appear empathy to them and improve the communication with subordinates [14], [22] suggested that (IJ) breakdown into two parts called interpersonal justice and information justice, and confirmed this model empirically by [23]. Interpersonal justice refers to the level of respect, honesty, dignity and respect to individuals by the authorities or by third parties which related to carry out procedures [23]. Information justices refer to clarify and justify why these procedures used and why outcomes distributed in these methods [23]. As long interactional dimension consists of informational and interpersonal justice this study will focus only on interactional justice which covers both informational and interpersonal justice.

\section{Organization Justice dimensions and Job Satisfaction}

Job satisfaction one of the important elements has been attracted the attention of (OJ) scholars and researchers. Meanwhile, most of the results reported there is a positive and significant relationship between these two variables. (OJ) its important element of JS and (OJ) can improve and increase (JS) among staff [8]. High level of organizational justice leads to increase job satisfaction in the organization among employees' and indicates more eager to achieve the organizational objectives [7]. Meta-Analytic Review conducted by [23] showed distributive and (IJ) positively correlated with some sub-dimensions of JS, while other subdimensions negatively correlated with JS.

Likewise, payment not enough to get employees satisfaction there are several elements significant correlated with JS such as promotion, workload and satisfaction with current work [24]. Theoretically, all the aspects of OJ predict JS [2]. However, the relation and impact among justice dimensions and JS empirically tend to be contrast, such as [2], [23] reported distributive justice has been more important and predictor to JS than procedural and interactional justice. contrary to others [25] reported only procedural justice impact on JS, while distributive justice has non-significant impact on JS. In another study, in the context of Thailand [12] concluded that (DJ) and (PJ) has no impact on JS. Another study conducted in context of Turkey, bank sector by (Bayarçelik \& Findikli, 2016) reported interactional has no significant effect on JS , on the other hand found distributed and procedural significant impact on JS. Meta-analysis by [26] reported there is a positive correlation between (DJ), (PJ) and (JS) degree of correlation are 0.35 and 0.36 respectively. another two studies conducted in Middle East countries which 
our study focus in this area by [27] (Fernandes \& Awamleh, 2006) in United Arab Emirates (UAE) and concluded JS affected by (DJ) and (IJ) but not, procedural justice. and study by [5] in Jordan and reported JS affected by organizational justice. according to the above clearly shown, there is a contrast in result among the dimensions of organizational justice in a different context may due the context of study or the sector which the study conducted or the culture, even widely accepted and confirmed the positive and significant impact among these dimensions and JS. to solve this contrast and exam these dimensions in the context of Iraq particularly among academic staff, study propose the following hypotheses, similar Proposition confirmed by [28].

H1: DJ is positively impact on JS among academic staff.

$\mathrm{H} 2$ : PJ is positively impact on JS among academic staff.

H3: IJ is positively impact on JS among academic staff.

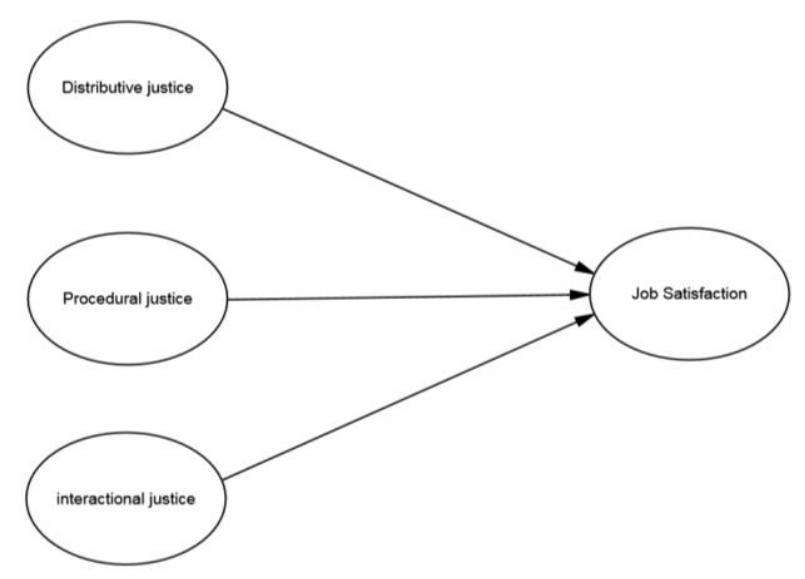

\section{Methodology}

Fig. 1. Framework of study

The sample size of this study consisted of 210 teachers who teaching in 8 official secondary schools during the 2018-2019 academic year in Heet city- the province of Al Anbar, Iraq. The study was deployed Stratified random sampling technique, the selection based on the number of teachers in each school. The Questionnaires were distributed by self-administration total valid Questionnaires 98. The data were analysed by statistical package for the social sciences (SPSS) version 23.

\section{Measures}

The questionnaire items were translated into Arabic language because all the items were adapted from previous studies in the English language, "translation-back translation" process [29]. Five- point Likert- scale were used from $1=$ strongly disagree to $5=$ strongly agree. Organizational justice consists of three dimensions and measured it as following:

Distributive justice which focuses to measured equality and equity through perceived of teachers. measured by 5 items adapted from [20]. Procedural justice refers to the rareness of bias, truth, ethics of process and evaluates the decision-making. This dimension measured by 6 items adapted from [20]. Interactional justice measured 6 items adapted from [21]. Job satisfaction measured by 5 items adapted from [1] which focused on measuring the level of satisfaction among school teachers.

\section{Data Analysis}

In this section, the results will be starting with demographic characteristics as represented in Table 1 . The majority of the respondents Male with $60 \%$ while $40 \%$ are Female. The largest response for this survey was with age group of 40 to 49 (43\%) and close to this result was with 
the group of 30 to 39 (37\%) while the young group below 30 years are $4 \%$ and above 60 years $5 \%$. As expected in Qualifications, most (81\%) of the respondents with bachelor's degree while (9\%) hold Master degree, Diploma with $(6 \%)$ and only $(3 \%)$ holding $\mathrm{PhD}$. A large proportion (34\%) 11to 15 years working experience while (32\%) more than 26 years working experience, $(13 \%)$ between $23-45$ and only $(8 \%)$ between $16-20$ years.

Table 1. Demographic description

\begin{tabular}{|l|l|r|r|}
\hline \multicolumn{2}{|l}{} & Count & Column N \% \\
\hline \multirow{3}{*}{ Gander } & Male & 59 & $60.2 \%$ \\
\cline { 2 - 4 } & Female & 39 & $39.8 \%$ \\
\hline \multirow{5}{*}{ Que } & Below 30 & 4 & $4.1 \%$ \\
\cline { 2 - 4 } & $30-39$ & 36 & $36.7 \%$ \\
\cline { 2 - 4 } & $40-49$ & 42 & $42.9 \%$ \\
\cline { 2 - 4 } & $50-59$ & 11 & $11.2 \%$ \\
\cline { 2 - 4 } & 60 and above & 5 & $5.1 \%$ \\
\hline \multirow{5}{*}{ Tenure } & Bachelor & 80 & $81.6 \%$ \\
\cline { 2 - 4 } & Master & 9 & $9.2 \%$ \\
\cline { 2 - 4 } & Diploma & 6 & $6.1 \%$ \\
\cline { 2 - 4 } & PhD & 3 & $3.1 \%$ \\
\hline & $11-15$ years & 11 & $34.7 \%$ \\
\cline { 2 - 4 } & less than 10 years. & 8 & $11.2 \%$ \\
\cline { 2 - 4 } & $16-20$ & 13 & $8.2 \%$ \\
\cline { 2 - 4 } & $23-45$ & 32 & $13.3 \%$ \\
\cline { 2 - 4 } & more than 26 & & $32.7 \%$ \\
\hline
\end{tabular}

\section{Validity and Reliability}

Cronbach's alpha refers to assess internal consistency and clarify how the items are associated with each other. Cronbach's alpha greater than .80 considered good. Table 2 shown all the factors level are greater than 0.885 which reflect a good level of reliability. Meanwhile, all factors are with good factor loading values, all the factor loading greater than 0.70 and significant.

Table 2. Validity and Reliability

\begin{tabular}{|c|c|c|c|}
\hline Variables & items & Factor loading & Cronbach alpha \\
\hline & JS1 & .895 & \\
Job & JS2 & .892 & .904 \\
satisfaction & JS3 & .903 & \\
& JS4 & .921 & \\
& JS5 & .623 & \\
DJ & DJ1 & .934 & \\
& DJ2 & .835 & .922 \\
& DJ3 & .860 & \\
& DJ4 & .872 & \\
& DJ5 & .860 & \\
& PJ1 & .752 & .903 \\
& PJ2 & .878 & \\
& PJ3 & .816 & \\
& PJ4 & .852 & \\
& PJ5 & .812 & \\
& PJ6 & .841 & \\
& IJ1 & .719 & \\
& IJ2 & .885 & \\
& IJ3 & .881 & \\
& IJ4 & .768 & \\
& IJ5 & .768 & \\
& IJ6 & .775 & \\
\hline
\end{tabular}

Note: DJ: Distributive justice, PJ: Procedural justice, IJ: Interactional justice 
Table 3 describes the Correlation matrix of all the variables which used in this study DJ, PJ, IJ, and JS are positive and significant correlated. Moreover, DJ more important in predicting JS $(\mathrm{r}=.829)$. Similarly, procedural justice more important in explaining JS $(\mathrm{r}=.450)$ and then interactional justice less than the previous two variables but positive and significant with $(\mathrm{r}=.257)$. Further, the high correlation was shown between distributive justice and procedural justice $(\mathrm{r}=.466)$.

Table 3. Correlation

\begin{tabular}{|c|c|c|c|c|}
\hline \\
\hline Variables & DJ & PJ & IJ & JS \\
\hline $\mathrm{DJ}$ & 1 & $.466 * *$ & .142 & $.829 * *$ \\
\hline PJ & & 1 & $.376 * *$ & $.450 * *$ \\
\hline IJ & & & 1 & $.257 *$ \\
\hline JS & & & & 1 \\
\hline
\end{tabular}

To test the three hypotheses, which consists of components of OJ toward JS.

First hypothesis DJ toward JS reported as shown in table 4 estimated regression statistically significant at $(P .000<0.05)$. Dependent variable JS explained the variance by 0.708 . However, this was supported by the correlation that showed a positive and significant relationship between DJ and JS r=0.829. Through the rank of a parameter of the standardised beta showed the distributive highly impact on job satisfaction. These results support $\mathrm{H} 1$ distributive justice significantly influences on job satisfaction. however, DJ index $(\beta=0.797)$ is a significant and positive impact on JS of academic staff. Second hypothesis PJ toward JS result showed estimated regression statistically non-significant on JS at $(P .627>0.5)$. the rank of a parameter of standardised beta indicated PJ does not impact on JS among schoolteachers.

These results do not support H2. meanwhile, PJ index $(\beta=0.029)$ is a significant and positive impact on JS of academic staff.

Third hypothesis IJ toward JS the regression statistically significant on JS see table 4 at $(P .030<0.5)$. parameter of the standardised beta showed the PJ impact on job satisfaction.

These results support H3 IJ significantly influences on JS. Foremother IJ index $(\beta=0.133)$ is a significant and positive impact on JS of academic staff.

Table 4. Regression

\begin{tabular}{|c|c|c|c|c|}
\hline Hypotheses & Beta & P value & Sig. & Remark \\
\hline DJ JS & .797 & .000 & $<0.5$ & Supported \\
\hline PJ JS & .029 & .672 & $>0.5$ & Not supported \\
\hline IJ JS & .133 & .030 & $<0.5$ & Supported \\
\hline
\end{tabular}

\section{Discussion}

Ensuring justice and equity in the schools or organisations among teachers or employees may create a great challenge. That's is not surprising several researchers, schoolers and organizations have empirically exam the organisational justice in the workplace (Theo and Lim, 2001). The fairness and just environment for various categories of schools could lead to increase the teacher's productivity and efficiency. This study tried to examine how OJ dimensions predict JS among teachers in Heet secondary schools. The results of this study expand the previous studies results which reported distributive and interactional justices are significantly impacting on job satisfaction similarly, [3], [8], [4] and this confirmed by correlations matrix which shown high correlations among these three justice dimensions. The greater interest that DJ has reported a stronger and could be the most important impact on JS than interactional and 
PJ, this result indicating the schools' directors should pay more attention to methods distribute which are related to schedule loads, rewards and responsibilities among teachers, similar result found with [2]. Job satisfaction significantly impacted by interactional justices. This indicates the schools' directors need to ceaselessly evaluate and enhance the relationship with teachers such as increasing the level of trust, respect and honest also, the act and interact way with their teachers and avoid the conflict or misunderstandings. study findings provide support for previous studies by [11], [4] that reported positive and significant effect of DJ and IJ on JS among schools' teachers. a potential reason that the schools' teachers would assume to given fair share in the distribution of resources within the of school. Thus, when the managers treat teachers in a brusque and offensive manner, they will feel not satisfy and this could lead eventually impact their outcome and productivity. In general, the study findings emphasize the importance that schools teachers attach to fairness and equality in the management of schools. taking into account Iraq facing several issues such as security issues, financial issues, services issues and school's infrastructure issues which negatively affected to teaching system and schools. This study found the procedural justice non-significantly impact of job satisfaction among schools teachers in Heet, This is may the teachers look to procedural justice dimension out of equation because of the environment or policy of public schools in Iraq which is different from the private sector in promotions, salary and employment etc, it is related to government policy.

On other word teachers in secondary schools reducing the importance and impact of procedural justice on job satisfaction because of prevailing environmental and policy dimensions in the country like Iraq. the same results reported by [27], [12] which found job satisfaction does not affected by PJ.

\section{Conclusion}

Results of this study in line with most of the previous studies conducted to exam the impact of organizational justice on job satisfaction. However, results indicated that the high of fairness in schools will lead to high job satisfaction. This result helps school's administration to manage the schools and understand teachers desire better than before which cold to increase job satisfaction among schools' teachers. Lastly, teachers, when feel treated fairly from school administration and the rewards are distributed fairly and equitable in the school will increase job satisfaction and could increase their productivity and performance.

Study findings have implications for future studies in the context of Iraq. However, can't generalize this result due to the study conducted only in one area. the future studies can exam the OJ and JS in private schools or in public schools with more than one area, furthermore, can exam these variables in bank sector or health sector, especially the context of Iraq suffering from limited studies in most of the sectors.

\section{REFERENCES}

1. Spector, P. E. (1997). Job satisfaction: Application, assessment, causes, and consequences (Vol. 3). Sage publications.

2. Abekah-Nkrumah, G., \& Atinga, R. A. (2013). Exploring the link between organisational justice and job satisfaction and performance in Ghanaian hospitals: Do demographic factors play a mediating role? International Journal of Workplace Health Management, 6(3), pp. 189-204. https://doi.org/10.1108/IJWHM-04-2011-0011

3. Hao, Y., Hao, J., \& Wang, X. (2016). The relationship between organizational justice and job satisfaction: Evidence from China. Journal of Chinese Human Resource Management, 7(2), pp. 115128. https://doi.org/10.1108/JCHRM-07-2016-0012 
4. Zainalipour, H., Fini, A. A. S., \& Mirkamali, S. M. (2010). A study of relationship between organizational justice and job satisfaction among teachers in Bandar Abbas middle school. ProcediaSocial and Behavioral Sciences, 5, pp. 1986-1990. https://doi.org/10.1016/j.sbspro.2

5. Greenberg, J. (1987). A Taxonomy of Organizational Justice Theories. Academy of Management Review. https://doi.org/10.5465/amr.1987.4306437

6. Brief, A. P. (1998). Attitudes in and around organizations. Thousand Oaks, CA: Sage Publications.

7. Bayarçelik, E. B., \& Findikli, M. A. (2016). The Mediating Effect of Job Satisfaction on the Relation Between Organizational Justice Perception and Intention to Leave. Procedia - Social and Behavioral Sciences. https://doi.org/10.1016/j.sbspro.2016.11.050

8. Haryono, S., Ambarwati, Y. I., \& Md Saad, M. S. (2019). Do organizational climate and organizational justice enhance job performance through job satisfaction? A study of Indonesian employees. Academy of Strategic Management Journal, 18(1), pp. 1-6.

9. Ahmad, M. abdul aziz, \& Jameel, A. S. (2018). Factors Affecting on Job Satisfaction among Academic Staff. Polytechnic Journal, 8(2), pp. 119-128. https://doi.org/10.25156/ptj.2018.8.2.161

10. Jameel,A.S. and Ahmed,A.R.(2019). Leadership and Performance of Academic Staff in Developing Countries. In Proceedings of the 33rd International Business Information Management Association (IBIMA), ISBN: 978-0-9998553-4-6, 10-11 April, 2019, Granada, Spain 6101-6106.

11. Nojani, M. I., Arjmandnia, A. A., Afrooz, G. A., \& Rajabi, M. (2012). The Study on Relationship between Organizational Justice and Job Satisfaction in Teachers Working in General, Special and Gifted Education Systems. Procedia - Social and Behavioral Sciences, 46, pp. 2900-2905. https://doi.org/10.1016/j.sbspro.2012.05.586

12. Potipiroon, W., \& Rubin, E. V. (2018). Who Is Most Influenced by Justice Perceptions? Assessing the Role of Occupational Status. Review of Public Personnel Administration, 38(3), pp. 271-302. https://doi.org/10.1177/0734371X16660156

13. Greenberg, J. (1982). Approaching Equity and Avoiding Inequity in Groups and Organizations. In Equity and Justice in Social Behavior. https://doi.org/10.1016/b978-0-12-299580-4.50017-3

14. Greenberg, J. (1990b). Employee Theft as a Reaction to Underpayment Inequity: The Hidden Cost of Pay Cuts. Journal of Applied Psychology. https://doi.org/10.1037/0021-9010.75.5.561

15. Lambert, E. G., Keena, L. D., Leone, M., May, D., \& Haynes, S. H. (2019). The effects of distributive and procedural justice on job satisfaction and organizational commitment of correctional staff. Social Science Journal. https://doi.org/10.1016/j.soscij.2019.02.002

16. Greenberg. (1990a). Looking fair vs. being fair: Managing impressions of organizational justice. Research In Organizational Behavior. https://doi.org/10.1037/031239

17. Greenberg, J. (1990c). Organizational Justice: Yesterday, Today, and Tomorrow. Journal of Management, 16(2), pp. 399-432. https://doi.org/10.1177/014920639001600208

18. Lind, E. A., \& Tyler, T. R. (1988). The social psychology of procedural justice. New York, NY: Plenum Press.

19. Leventhal, G. S. (1980). What should be done with equity theory? New approaches to the study of fairness in social relationships. In Social exchange: Advances in theory and research.

20. Bies, R. J., \& Moag, J. S. (1986). Interactional justice: communication criteria of fairness. In Research in negotiations in organizations. https://doi.org/10.1111/j.1559-1816.2004.tb02581.x

21. Greenberg, J. (1993). Title: The Social Side of Fairness: Interpersonal and Informational Classes of Organisational Justice. Justice in the Workplace: Approaching Fairness in Human Resource Management.

22. Colquitt, J. a, Conlon, D. E., Wesson, M. J., Porter, C. O., \& Ng, K. Y. (2001). EBSCOhost: Justice at the Millennium: A Meta-Analytic Review of 25 Years of Organizati. Journal of Applied Psychology. https://doi.org/10.1037//0021-9010.86.3.425

23. McAuliffe, E., Manafa, O., Maseko, F., Bowie, C., \& Emma White. (2009). cadres Understanding job satisfaction amongst in Malawi: the contribution of organisational justice. Reproductive Health Matters, 17(33), pp. 80-90.

24. Lambert, E. G., Hogan, N. L., \& Griffin, M. L. (2007). The impact of distributive and procedural justice on correctional staff job stress, job satisfaction, and organizational commitment. Journal of Criminal Justice, 35(6), pp. 644-656. https://doi.org/10.1016/j.jcrimjus.2007.09.001

25. Viswesvaran, C., \& Ones, D. S. (2002). Examining the construct of organizational justice: A metaanalytic evaluation of relations with work attitudes and behaviors. Journal of Business Ethics. https://doi.org/10.1023/A:1015820708345

26. Fernandes, C., \& Awamleh, R. (2006). Impact of organisational justice in an expatriate work environment. Management Research News, 29(11), pp. 701-712. https://doi.org/10.1108/01409170610716016 
27. Dong, L. N. T., \& Phuong, N. N. D. (2018). Organizational Justice, Job Satisfaction and Organizational Citizenship Behavior in Higher Education Institutions: A Research Proposition in Vietnam. The Journal of Asian Finance, Economics and Business, 5(3), pp. 113-119. https://doi.org/10.13106/jafeb.2018.vol5.no3.113

28. Brislin, R. W. (1980). Translation and content analysis of oral and written materials. Handbook of cross-cultural psychology.

29. Suifan, T. S., Diab, H., \& Abdallah, A. B. (2017). Does organizational justice affect turnover-intention in a developing country? The mediating role of job satisfaction and organizational commitment. Journal of Management Development, 36(9), pp. 1137-1148. https://doi.org/10.1108/JMD-02-2017-0048

30. Qureshi, H., Frank, J., Lambert, E. G., Klahm, C., \& Smith, B. (2017). Organisational justice's relationship with job satisfaction and organisational commitment among Indian police. The Police Journal: Theory, Practice and Principles, 90(1), pp. 3-23. https://doi.org/10.1177/0032258x16662684

\section{Article history:}

- Received 30 August 2019

- Accepted 18 November 2019 